\title{
The novel peptide HEADY specifies apical fate in a simple radially symmetric metazoan
}

\author{
Jan U. Lohmann ${ }^{1}$ and Thomas C.G. Bosch ${ }^{2,3}$ \\ Zoological Institute, University of Jena, 07743 Jena, Germany
}

\begin{abstract}
One of the first steps in animal development is axis formation, during which an uneven distribution of signals and/or transcription factors results in the establishment of polarity in the embryo. Hydra, one of the simplest metazoan animals, shows characteristics of a permanent embryo. Even adult polyps have a striking capacity to regenerate, suggesting that molecular mechanisms underlying de novo pattern formation are permanently active and self regulatory. Here we show that HEADY, a short, amidated peptide, plays a central role in the specification of apical fate in this simple metazoan. The HEADY gene, whose transcripts accumulate at the apical organizing center, is required for specification of apical fate, as disruption of $H E A D Y$ function by dsRNA mediated interference (RNAi) results in severe defects in head formation. Conversely, an instructive role of HEADY in head specification is demonstrated by the application of synthetic HEADY peptide, which induces formation of secondary axes with head morphology. Thus, the HEADY peptide acts as developmental switch to pattern the apical-basal axis of Hydra, providing a first insight into how initial asymmetry is specified in lower metazoan animals.
\end{abstract}

[Key Words: Hydra; peptides; head induction; regeneration; DD-PCR; RNAi]

Received August 7, 2000; revised version accepted September 26, 2000.

Hydra is a solitary freshwater polyp and a member of the basal phylum of cnidaria. Animals from this phylum were the first in metazoan evolution to develop a complex body structure composed of specialized tissues. $\mathrm{Hy}$ dra polyps are radially symmetric and, therefore, have only one prominent axis, the apical-basal body axis. Head and foot are the only differentiated structures of the animal and define the opposite ends of this axis (Bosch 1998). Polyps proliferate asexually by budding, a process during which a secondary polyp forms in the lower gastric region of the parental animal. Hydra has a diploblastic body plan and consists of only two cell layers. Cell proliferation takes place continuously in both of the cell layers but is restricted to the gastric region of the animal. Mitotically produced cells are displaced toward head and foot, where they differentiate to form the appropriate structures (David and Campbell 1972). Cells are continuously lost from the adhesive foot and the tentacles, which are used to catch prey. Therefore, tissue dynamics have to be tightly controlled to maintain homeostasis between the two cell layers as well as between the different cell types within the layers. To maintain this steady state of proliferation and differentiation, un-

Present addresses: ${ }^{1}$ The Salk Institute for Biological Studies, La Jolla, CA 92037, USA; ${ }^{2}$ Zoologisches Institut der Universität zu Kiel (Biozentrum), 24098 Kiel, Germany.

${ }^{3}$ Corresponding author.

E-MAIL tbosch@zoologie.uni-kiel.de; FAX 49-431-880-4747.

Article and publication are at www.genesdev.org/cgi/doi/10.1101/ gad. 830100 . derlying developmental signals have to be continuously active to provide cells with positional information throughout the entire life cycle of the animal (Bosch 1998). The molecular nature of these signals is still largely unknown, but there is good evidence that patterning in Hydra is governed by self-regulatory interacting gradients of diffusable factors (Meinhardt 1993). It is thought that independent reaction-diffusion systems regulate the development of the head and foot, as well as the formation of buds. The continuous presence of these developmental signals gives even adult polyps a remarkable ability to fully regenerate lost body structures. These observations suggest that in Hydra axis formation, fate specification and differentiation are inseparably linked and continuously active processes. In this study, we demonstrate that in addition to such continuously active processes, HEADY, a newly discovered signaling peptide, acts transiently to specify the apical end of the body axis.

\section{Results}

Isolation and sequence analysis of the HEADY $c D N A$

To identify genes involved in axis formation and patterning in simple metazoans, we developed a screening strategy that makes use of the remarkable regeneration capacity of the freshwater polyp Hydra. Intact polyps were dissociated into single cells and kept in suspension for 4 $\mathrm{h}$ before they were reaggregated by centrifugation (Gierer et al. 1972). By de novo axis formation, these cell aggre- 


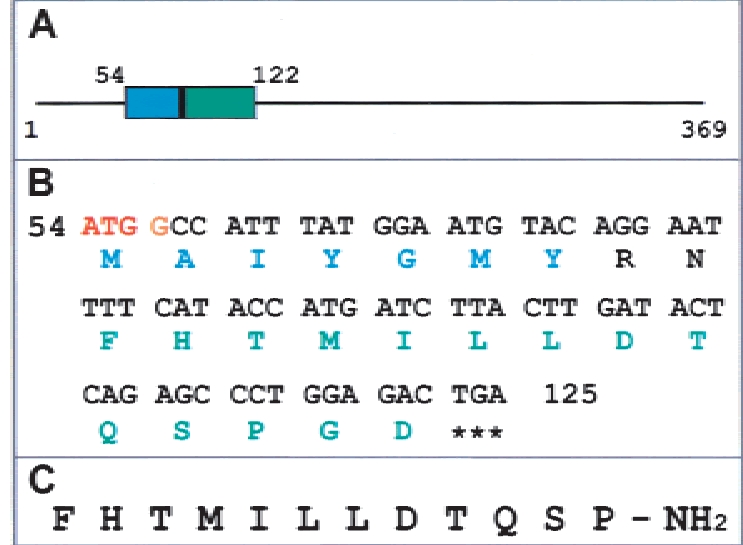

Figure 1. HEADY mRNA and protein structure. $(A)$ Structure of the HEADY transcript. Nucleotides 54-122 encode the HEADY precursor protein. The putative leader sequence is shown in blue, processing site in black, and the propeptide in green. The complete HEADY cDNA sequence has been deposited in GenBank under accession AF188478. (B) cDNA and deduced amino acid sequence of the HEADY precursor. The ATG triplet in position 54 is the first start codon in the transcript. The G in the fourth position indicates that it is a preferred site for initiation of translation (Kozak 1997). The deduced amino acid sequence of the HEADY precursor is shown below the cDNA sequence. $(C)$ Sequence of the mature HEADY peptide.

gates regenerate into intact polyps within a few days (Gierer et al. 1972). RNA samples were taken from intact polyps, from cells 2 min after dissociation, from cells $4 \mathrm{~h}$ after dissociation, from cells $1.5 \mathrm{~h}$ after reaggregation, and from cells $20 \mathrm{~h}$ after reaggregation. These RNA samples were then subjected to nonradioactive differential display PCR (Liang and Pardee 1992; Lohmann et al. 1995) to monitor gene expression during de novo axis formation. Fourteen of 450 transcripts $(3 \%)$ analyzed in two independent experiments were found to be differentially expressed. One of these was represented in a short cDNA of $\sim 380$ bases predicted to encode a short peptide that we named HEADY (Fig. 1). Sequence analysis revealed an open reading frame of 69 bases coding for the peptide precursor. By analogy with other cnidarian peptides (Darmer et al. 1998), the propeptide could be cleaved from the precursor after the motif arginine-asparagine. As a C-terminal glycine-aspartate motif was recently found to serve as amidation signal in the cnidarian peptide Hym-357 (Yum et al. 1998a), the mature Heady peptide is predicted to have the structure FHTMILLDTQSP-NH $\mathrm{N}_{2}$ (Fig. 1C). To confirm the structure-function relationship of the HEADY peptide, we investigated the biological activity of synthetic fulllength and amidated peptide FHTMILLDTQSP- $\mathrm{NH}_{2}$, the $\mathrm{N}$-terminal deleted version TQSP- $\mathrm{NH}_{2}$, and the two nonamidated peptides FHTMILLDTQSPGD and FHTMILLDTQSPG (see Materials and Methods). Only the full-length and amidated peptide showed significant biological effects, confirming the predicted peptide structure.

\section{Expression of HEADY is transient and specific to apical organizing centers}

HEADY RNA expression is spatially and temporally regulated (Fig. 2). Using RT-PCR, we found that $H E A D Y$, which was only weakly expressed in intact pol-

Figure 2. Expression of $H E A D Y$ is transiently induced during apical fate specification. (A) Expression of HEADY during head regeneration. RT-PCR revealed a maximum of $H E A D Y$ expression $6 \mathrm{~h}$ after onset of head regeneration (R6). After $8 \mathrm{~h}$ (R8) expression was again reduced considerably. Actin was used as control for equal loading of $\mathrm{cDNA}$; minus sign indicates water control. (B) Whole-mount in situ hybridization of a head-regenerating animal $6 \mathrm{~h}$ after decapitation. $(C)$ Cells expressing $H E A D Y$ were located in the endoderm at the apical-most position of the regenerating tip (30 min of color reaction), and $(D)$ $90 \mathrm{~min}$ of color reaction revealed that the level of HEADY mRNA decreases in a gradient from apical to more basal tissue. $(E)$ Intact polyp, no staining could be detected. $(F-I)$ Expression of HEADY during budding. (F) HEADY expression could be detected first in bud stage 3 (Otto and

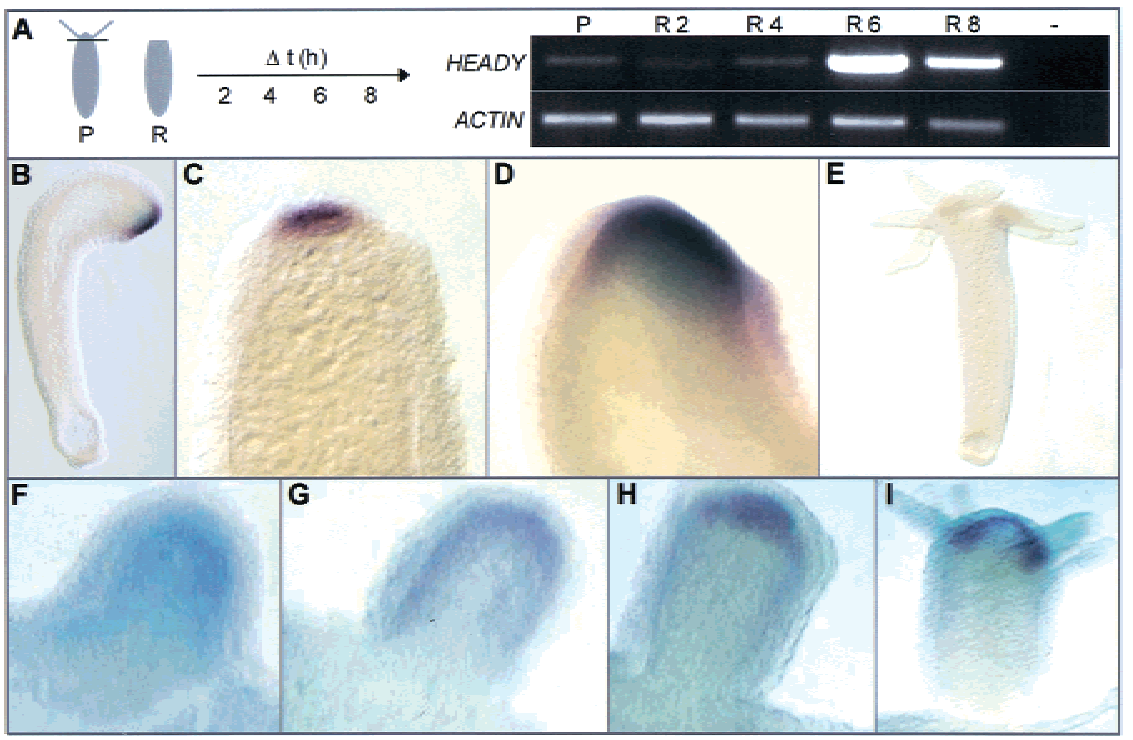
Campbell 1977). (G) During intermediate budding stages (stage 5), HEADY transcripts were restricted to the endoderm with increased amounts of mRNA at the apical tip of the bud. $(H)$ During later stages of budding, with tentacles starting to be formed, HEADY expression was strong and restricted to the apical-most cells of the endoderm. (I) In a mature bud (bud stage 9) that will detach from the parental polyp within the next few hours, $H E A D Y$ transcripts were located in the apical most endoderm only. No transcripts were found in the tentacles. 
yps, is transiently up-regulated $6 \mathrm{~h}$ after decapitation (Fig. 2A). The induction was similar regardless of whether animals were bisected just below the tentacles or in the midgastric region. This was surprising because the potential for head regeneration decreases from apical to basal positions (Bosch 1998), leading to a delayed formation of head structures from basal tissue. Correspondingly, the induction of genes linked to head differentiation in Hydra is delayed when animals are decapitated in more basal positions (Endl et al. 1999; Technau and Bode 1999|. These results suggest that the HEADY peptide is not involved in head differentiation, which is position dependent, but rather in the preceding fate specification. No increase in HEADY expression could be observed when the foot was removed, confirming that the induction was specific for apical determination and was not caused by simple wounding. In situ hybridization (Martinez et al. 1997) showed that during apical fate specification HEADY transcripts accumulate in a small number of endodermal cells at the regenerating tip, with highest levels in the apical-most cells (Fig. 2B-D). In intact animals, no localized accumulation of HEADY transcripts could be detected (Fig. 2E).

To confirm that HEADY activity participates in the general mechanism to specify the apical end of the body axis and is not restricted to head regeneration, we analyzed HEADY expression during budding. During this process, a secondary axis is induced without injury. From bud stage 3 (Otto and Campbell 1977) on, HEADY transcripts accumulated evenly throughout the endoderm of the bud (Fig. 2F). During subsequent development of the bud, expression was progressively confined to the apical end (Fig. 2G-I). A few hours after the bud detached from the parental animal, HEADY transcripts were no longer present in the head of the young polyp (Fig. 2E). Thus, early apical fate specification and HEADY expression are intimately linked.

\section{HEADY peptide is stored in vesicles in endodermal epithelial cells}

To localize the mature HEADY peptide in Hydra tissue, a polyclonal anti-HEADY antiserum was raised in chicken. In competitive ELISA, a 1:8000 dilution of the antiserum was shown to bind to the HEADY peptide even in the presence of $10 \times$ molar excess of unrelated protein (data not shown), indicating specific affinity to the HEADY peptide. Using this antiserum for wholemount immunocytochemistry, we detected HEADY peptide in vesicles of endodermal epithelial cells, evenly distributed throughout the gastric tissue but almost absent in head or foot (Fig. 3C). HEADY seemed to be released in early stages of bud formation, as stained vesicles could not be detected in this tissue (Fig. 3D). Similarly, in head regeneration experiments, no staining was seen in the regenerating tip immediately following decapitation (data not shown). Staining was reestablished $8 \mathrm{~h}$ after the onset of regeneration, indicating a transient and local release of HEADY peptide in tissue undergoing apical fate specification. Depletion of

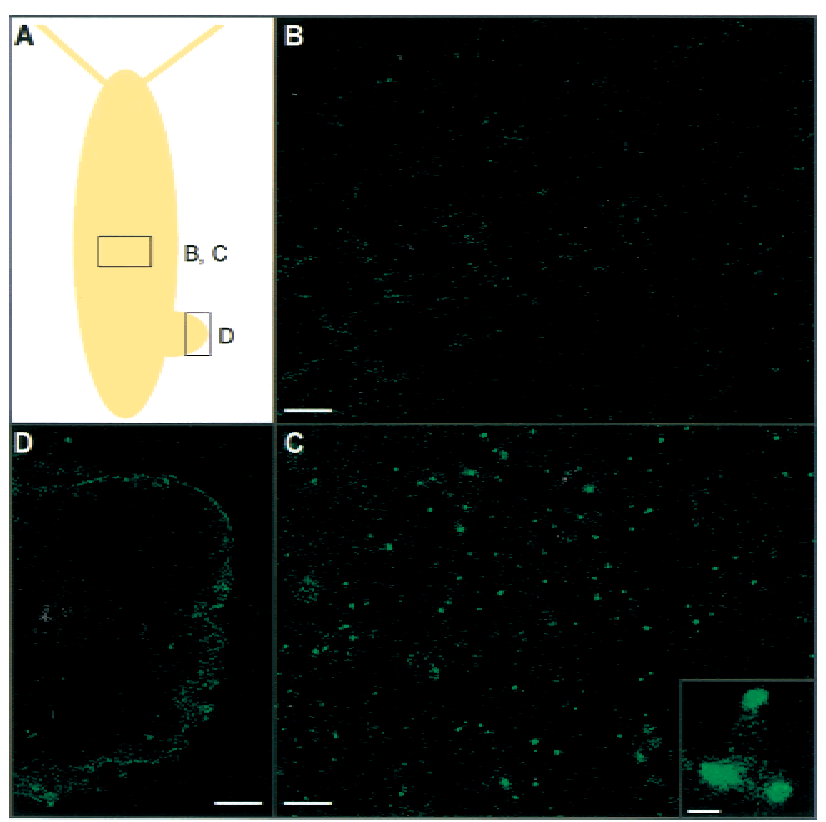

Figure 3. Immunolocalization of mature HEADY peptide in vesicles of endodermal epithelial cells in the gastric region. Confocal micrographs of whole-mount immunocytochemistry are shown. Scale bars indicate $30 \mu \mathrm{m}$. (A) Representative pictures $(B, C, D)$ were taken at the sites indicated by squares. The confocal plane was set to the endoderm. (B) Midgastric tissue stained with preimmune serum. No specific immunofluorescence could be detected. $(C)$ Midgastric tissue stained with antiHEADY serum. Fluorescence was observed in endodermal epithelial cells. Higher magnification (insert in $C$, scale bar $=1 \mu \mathrm{m}$ ) revealed that each spot of fluorescence consists of several HEADY-containing vesicles. About $20 \%$ of the endodermal epithelial cell population was found to contain HEADY-positive vesicles. (D) Tip of a young bud (stage 3) stained with antiHEADY serum. Absence of HEADY-containing vesicles suggested that it had been released in the course of early bud formation. Staining at the edge of the tissue sample could also be detected with the preimmune serum and was regarded to be unspecific.

HEADY-containing vesicles was followed by up-regulation of $H E A D Y$ transcription as revealed by in situ hybridization and RT-PCR (see Fig. 2). Strikingly, although expression was up-regulated during the early specification of the apical axis end, neither HEADY transcripts nor the mature peptide were differentially localized in the adult head (Fig. 2). This supports the view that HEADY plays a role only in the induction of the head, not in its maintenance.

\section{HEADY induction is absent in a regeneration-deficient mutant}

To further explore the correlation of head induction and $H E A D Y$ activity, we studied HEADY expression in the reg16 mutant, whose potential for head regeneration is strongly reduced (Sugiyama and Fujisawa 1977). In intact reg16 polyps, HEADY levels were not changed compared 
to the wild-type strain. In contrast to wild-type, however, HEADY expression was not induced in decapitated reg16 polyps. When the regeneration capacity of reg16 was restored by repeated wounding (Achermann and Sugiyama 1985) or treatment with the PKC activator TPA (Weinziger et al. 1994; Müller 1995), HEADY expression was restored to wild-type levels (data not shown), confirming a specific correlation between head induction and HEADY expression.

\section{HEADY is necessary for head induction}

To determine whether HEADY was required for head induction in wild-type polyps, we generated heady lossof-function animals by dsRNA-mediated interference (Fire et al. 1998). HEADY dsRNA was synthesized and electroporated into intact polyps according to previously established protocols (Lohmann et al. 1999). After $4 \mathrm{~d}$, polyps showed drastic depletion of $H E A D Y$ transcripts (Fig. 4B). When those HEADY loss-of-function animals were decapitated, their capacity to regenerate a new head was severely reduced compared with mock-electroporated animals (Fig. 4A,C). On average, head formation was delayed by about $2 \mathrm{~d}$ but was not completely blocked. This is compatible with HEADY expression being only reduced, not eliminated, by RNAi. Because of the continuous cell proliferation in Hydra, the amount of dsRNA per cell is increasingly diluted. Thus, the genesilencing effect is progressively decreased, allowing HEADY transcripts to accumulate with time. Therefore, residual $H E A D Y$ levels of as little as $10 \%$ may be sufficient to promote head regeneration, although at a slower rate. Alternatively, head induction might be redundantly regulated, with other factors partly substituting for HEADY activity.

No effect of heady loss of function was observed in foot-regenerating animals (data not shown), indicating an essential role for HEADY in the specification of the apical but not the basal end of the body axis.

\section{HEADY peptide is an inducer of apical fate}

Having demonstrated that HEADY is necessary for the specification of apical fate and, thus, head formation, we tested whether the HEADY peptide is also sufficient for head induction. Because a secondary head is induced during budding, we first studied the influence of synthetic HEADY peptide on this process. Newly detached polyps were continuously incubated for $12 \mathrm{~d}$ in $10^{-6} \mathrm{M}$ HEADY peptide, fed daily, and scored for number of buds. Exogenously applied HEADY caused budding to be initiated $\sim 1.5 \mathrm{~d}$ earlier compared to controls (Fig. 5A). Once the animals started to bud, however, the number of buds produced per day (budding rate) was not increased. As there was no influence of Heady on the rate of budding, the peptide does not appear to affect cell proliferation but, rather, to induce precocious secondary head formation. To verify this hypothesis, we tested the potential of HEADY to induce apical fate in lateral grafting experi-
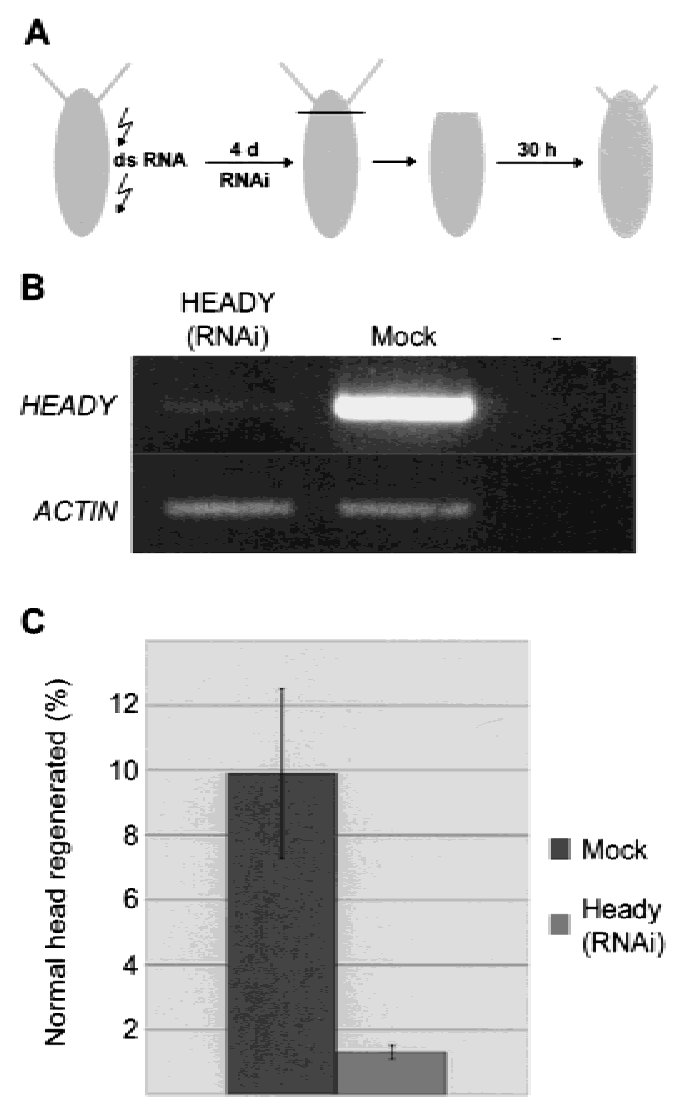

Figure 4. RNAi with HEADY disrupts head regeneration. (A) Schematic outline of the RNAi procedure (Lohmann et al. 1999). (B) Depletion of HEADY mRNA by RNAi as shown by RT-PCR using $H E A D Y$-specific primers. Actin was included as loading control. (C) RNAi of HEADY dsRNA reduced the rate of head regeneration $30 \mathrm{~h}$ after decapitation from $10 \%(n=99)$ in mock electroporated control animals to $1.3 \%(n=114)$ in $H E A D Y$ dsRNA electroporated animals. A total of 240 young polyps were electroporated with $20 \mu \mathrm{g}$ of $H E A D Y$ dsRNA or were mock electroporated. After $4 \mathrm{~d}$ of recovery, animals were decapitated and allowed to regenerate for $30 \mathrm{~h}$. Only fully regenerated heads (Lohmann et al. 1999) were scored.

ments. Using this assay, the morphogenetic activity of tissue can be tested without interference from cell proliferation effects. Polyps were continuously incubated in $10^{-6} \mathrm{M}$ peptide with daily feeding for $5 \mathrm{~d}$ and then used as donors for homotopic gastric transplantation. Small pieces of donor gastric tissue were transplanted into the same gastric position in untreated host polyps (Fig. 5B; Sugiyama 1982). Secondary axes with head morphology formed $30 \%$ of HEADY-treated implants, compared with only $10 \%$ in controls. Foot formation was markedly reduced in tissue treated with HEADY before transplantation, confirming that HEADY is a potent and specific inducer of apical fate.

\section{HEADY is not involved in maintaining the pattern} along the apical-basal axis

To elucidate whether HEADY also plays a role in continuous head formation in intact polyps, we examined 


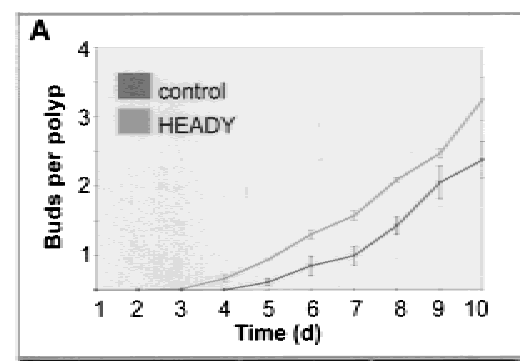

B

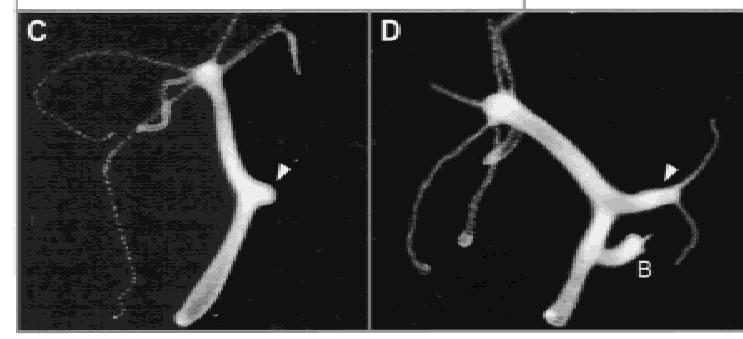

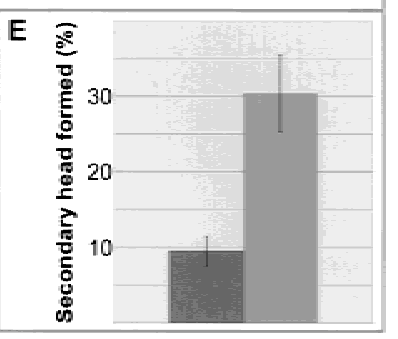

Figure 5. HEADY peptide affects head induction in Hydra. (A) Bud formation in HEADY-treated polyps occurred $1.5 \mathrm{~d}$ earlier than in untreated control animals ( $n=60$ polyps). The rate of budding, however, was not affected. (B) Experimental outline of grafting procedure (Sugiyama 1982). (C) Control implant (arrowhead) showing no differentiated structures. $(D)$ HEADY-treated implant (arrowhead) developing a secondary axis with head morphology. $B$, developing bud on the primary body axis. (E) Stimulation of secondary axis formation in transplanted tissue treated with HEADY. Five days after transplantation $30 \%(n=79)$ of the treated implants showed developed heads (see $D$ ), compared with $10 \%(n=75)$ in untreated control implants $(C)$. Foot formation was induced in $20 \%$ of control implants and was reduced to $13 \%$ in HEADY treated tissue. the expression of several developmental regulators in reaction to HEADY peptide treatment. Animals were incubated in $10^{-6} \mathrm{M}$ HEADY for $7 \mathrm{~d}$, followed by expression-analysis of the transcription factor genes Budhead (Martinez et al. 1997) and CnNK-2 (Grens et al. 1996), as well as the matrix metalloprotease gene FARM1 (Kumpfmüller et al. 1999) by in situ hybridization or RT-PCR. These genes have been shown to be sensitive to head-, foot-, or gastric-specific signals and appear to play essential roles in maintaining the pattern along the Hydra body axis (Grens et al. 1996, 1999; Martinez et al. 1997; Kumpfm̈ller et al. 1999). HEADY treatment did not influence their expression (data not shown), supporting the view that HEADY is involved in apical fate specification but does not act as a positional signal once the pattern along the apical-basal axis has been established.

\section{Discussion}

A screen for transcripts induced during de novo axis formation and morphogenesis in the basal metazoan Hydra resulted in the isolation of $H E A D Y$, an RNA coding for a short, amidated peptide. In this study, we demonstrated that the activity of the HEADY peptide is both necessary and sufficient to organize the apical end of the body axis in Hydra.

\section{HEADY $c D N A$ and protein structure}

The HEADY transcript has several unusual features. It is the shortest mRNA isolated from Cnidarians to date. Other cDNAs coding for peptide precursors isolated from Hydra so far range in size from $600 \mathrm{bp}$ to $1.5 \mathrm{~kb}$ (Darmer et al. 1998; Yum et al. 1998a). The HEADY cDNA exhibits a short open reading frame of 69 bases that codes for a single peptide. Previously described peptide precursors contain two to 11 individual peptides
(Darmer et al. 1998; Gajewski et al. 1998). Because of the small size of the HEADY precursor, it seems unlikely that the nascent protein is translocated to the endoplasmic reticulum (ER) during translation. Rather, it seems that the 23-amino acid precursor is translocated to the ER posttranslationally in a process similar to the one employed by the yeast $\alpha$ factor (Hansen et al. 1986). Although the native HEADY peptide has not been isolated from Hydra tissue so far, a number of experimental observations confirm that the isolated cDNA codes for the predicted active signaling molecule. First, depletion of HEADY transcripts by RNAi (loss of function) and the application of HEADY peptide to polyps (gain of function) result in opposite effects. Second, only the synthetic peptide of the predicted structure exhibits biological activity. Third, release of HEADY peptide from vesicles is associated with colocalized up-regulation of HEADY transcription.

\section{HEADY, a potent, transient inducer of apical fate}

The continuous proliferation and differentiation of cells in Hydra suggests that underlying developmental programs are continuously active. This is reflected in theoretical models based on reaction-diffusion equations that are capable to simulate all aspects of Hydra development (Meinhardt 1993). These models predict self-regulatory morphogen gradients that are continuously present and active throughout the entire life cycle of the polyp. Classical transplantation experiments have revealed a number of morphogenetic activities in Hydra tissue, including head or foot induction or inhibition (MacWilliams 1983a,b). However, the underlying molecules have not been identified to date. The isolation and characterization of HEADY reveals that the regulatory network of head formation in simple metazoans is more complex than anticipated. The fact that HEADY expression does not follow the gradient of head activation capacity and 
the finding of local and transient release of the peptide demonstrates that HEADY is involved in the specification of apical fate rather than in the process of head differentiation. This is in contrast to all other genes that have been reported to be linked to head formation in Hydra (Shenk et al. 1993; Martinez et al. 1997; Endl et al. 1999; Technau and Bode 1999) and provides first evidence that apical fate determination and head formation are two closely linked but independent processes. Another candidate for one of the signals involved in head development is the neuropeptide head activator (HA; Schaller 1973). Although HEADY shares no sequence similarity with the HA, its effect on bud formation seems to be similar (Hobmayer et al. 1997). However, unlike HA, HEADY treatment does not increase the number of tentacles during head regeneration, suggesting that HEADY and HA act in distinct genetic pathways. Furthermore, HA is localized in the mature head (Hampe et al. 1999), where HEADY peptide is virtually absent.

\section{Peptides, key molecules in metazoan evolution}

A growing body of evidence indicates that peptides play important roles as developmental signals in lower metazoans. First, a large number of peptide signaling molecules have been isolated from Hydra and other Cnidarians by various experimental approaches (Bodenmüller and Schaller 1981; Leitz et al. 1994; Hoffmeister 1996; Takahashi et al. 1997, 2000). Recent experiments suggest that Hydra contains about 1000 distinct peptide molecules (T. Takahashi, T. Fujisawa, pers. comm.). In contrast, no molecule related to growth factors of higher animals has been isolated to date. Second, peptides serve in a variety of biological processes as diverse as metamorphosis induction (Leitz et al. 1994), muscle contraction (Yum et al. 1998b), nerve cell differentiation (Takahashi et al. 2000), or apical fate specification and, therefore, are not limited to certain aspects of development. Third, their small size makes peptides ideal molecules for traveling with ease in the interepithelial space to cause the long-range effects necessary for the establishment of morphogenetic gradients. Our data on the isolation and functional analysis of HEADY adds further support to the view that peptides have played a key role as developmental signals in metazoan evolution.

\section{Materials and methods}

\section{Animals}

Hydra magnipapillata polyps were cultured according to standard procedures at $18^{\circ} \mathrm{C}$.

\section{$P C R$}

HEADY cDNA was isolated from a DD-PCR reaction using poly $(\mathrm{A})+$ RNA from regenerating cell-aggregates and primers $\mathrm{T}_{(12)} \mathrm{AG}$ and AGTCAGCCAC. Primers 5'-AGTCAGCCACAG CAACATAGG-3' and 5'-AGTCAGCCACTCGGGGAGC-3' were used for specific quantitative RT-PCR. cDNA pools of 20 polyps were used as template for amplification of each time point. RACE PCR (Chenchik et al. 1996) was used to isolate the 369-bp HEADY cDNA.

\section{Antisera}

The anti-HEADY polyclonal antiserum was raised in chicken against KLH-coupled TQSP-NH $\mathrm{NH}_{2}$. FITC-conjugated antichicken Fab fragments were used as a secondary antibody.

\section{Peptide treatments}

Peptide stock solutions were kept as $10^{-3} \mathrm{M}$ at $-80^{\circ} \mathrm{C}$. Working solutions were prepared freshly for each experiment by diluting the stock to $10^{-6} \mathrm{M}$ with Hydra culture solution. To determine the structure of the mature and biologically active HEADY peptide, we tested peptides FHTMILLDTQSP- $\mathrm{NH}_{2}$ (predicted structure), TQSP-NH $\mathrm{NH}_{2}$ FHTMILLDTQSPGD, and FHTMILLDTQSPG in the budding assay as shown in Figure 5A. As only the predicted peptide was capable of influencing budding, we concluded that FHTMILLDTQSP- $\mathrm{NH}_{2}$ is the active form.

\section{TPA treatment}

Polyps were incubated in $30 \mathrm{nM}$ TPA (12-O-Tetradecanoylphorbol-13-acetat; Sigma) in Hydra culture solution for $20 \mathrm{~min}$ as described (Weinziger et al. 1994) and washed twice in culture solution immediately. After another $30 \mathrm{~min}$ in culture solution, experiments were carried out.

\section{Acknowledgments}

We thank Ingrid Endl for help with RNAi, Fumihiro Morishita for providing synthetic peptides, Charles N. David for discussion and providing the confocal microscopy facility and for, with Detlef Weigel, critically reading the manuscript. Supported by the Deutsche Forschungsgemeinschaft.

The publication costs of this article were defrayed in part by payment of page charges. This article must therefore be hereby marked "advertisement" in accordance with 18 USC section 1734 solely to indicate this fact.

\section{References}

Achermann, J. and Sugiyama, T. 1985. Genetic analysis of developmental mechanisms in hydra. X. Morphogenetic potentials of a regeneration-deficient strain (reg-16). Dev. Biol. 107: 13-27.

Bodenmüller, H. and Schaller, H.C. 1981. Conserved amino acid sequence of a neuropeptide, the head activator, from coelenterates to humans. Nature 293: 579-580.

Bosch, T.C. 1998. Hydra. In Cellular and molecular basis of regeneration: From invertebrates to humans (ed. P. Ferretti and J. Géraudie), pp. 111-134. Wiley, Sussex.

Chenchik, A., Diachenko, L., Moqadam, F., Tarabykin, V., Lukyanov, S., and Siebert, P.D. 1996. Full-length cDNA cloning and determination of mRNA $5^{\prime}$ and $3^{\prime}$ ends by amplification of adaptor-ligated cDNA. Biotechniques 21: 526534.

Darmer, D., Hauser, F., Nothacker, H.P., Bosch, T.C., Williamson, M., and Grimmelikhuijzen, C.J. 1998. Three different prohormones yield a variety of Hydra-RFamide (Arg-Phe$\mathrm{NH} 2$ ) neuropeptides in Hydra magnipapillata. Biochem. I. 
332: 403-412.

David, C.N. and Campbell, R.D. 1972. Cell cycle kinetics and development of Hydra attenuata. I. Epithelial cells. J. Cell. Sci. 11: 557-568.

Endl, I., Lohmann, J.U., and Bosch, T.C. 1999. Head-specific gene expression in Hydra: Complexity of DNA-protein interactions at the promoter of ks1 is inversely correlated to the head activation potential. Proc. Natl. Acad. Sci. 96: $1445-1450$.

Fire, A., Xu, S., Montgomery, M.K., Kostas, S.A., Driver, S.E., and Mello, C.C. 1998. Potent and specific genetic interference by double-stranded RNA in Caenorhabditis elegans. Nature 391: 806-811.

Gajewski, M., Schmutzler, C., and Plickert, G. 1998. Structure of neuropeptide precursors in cnidaria. Ann. NY Acad. Sci. 839: $311-315$.

Gierer, A., Berking, S., Bode, H., David, C.N., Flick, K., Hansmann, G., Schaller, H., and Trenkner, E. 1972. Regeneration of hydra from reaggregated cells. Nat. New Biol. 239: 98101.

Grens, A., Gee, L., Fisher, D.A., and Bode, H.R. 1996. CnNK-2, an NK-2 homeobox gene, has a role in patterning the basal end of the axis in hydra. Dev. Biol. 180: 473-488.

Grens, A., Shimizu, H., Hoffmeister, S.A., Bode, H.R., and Fujisawa, T. 1999. The novel signal peptides, pedibin and Hym346 , lower positional value thereby enhancing foot formation in hydra. Development 126: 517-524.

Hampe, W., Urny, J., Franke, I., Hoffmeister-Ullerich, S.A., Herrmann, D., Petersen, C.M., Lohmann, J., and Schaller, H.C. 1999. A head-activator binding protein is present in hydra in a soluble and a membrane-anchored form. Development 126: 4077-4086.

Hansen, W., Garcia, P.D., and Walter, P. 1986. In vitro protein translocation across the yeast endoplasmic reticulum: ATPdependent posttranslational translocation of the prepro- $\alpha$ factor. Cell 45: 397-406.

Hobmayer, B., Holstein, T.W., and David, C.N. 1997. Stimulation of tentacle and bud formation by the neuropeptide head activator in Hydra magnipapillata. Dev. Biol. 183: 1-8.

Hoffmeister, S.A. 1996. Isolation and characterization of two new morphogenetically active peptides from Hydra vulgaris. Development 122: 1941-1948.

Kozak, M. 1997. Recognition of AUG and alternative initiator codons is augmented by $\mathrm{G}$ in position +4 but is not generally affected by the nucleotides in positions +5 and +6 . EMBO $J$. 16: $2482-2492$.

Kumpfmüller, G., Rybakine, V., Takahashi, T., Fujisawa, T., and Bosch, T.C. 1999. Identification of an astacin matrix metalloprotease as target gene for Hydra foot activator peptides. Dev. Genes Evol. 209: 601-607.

Leitz, T., Morand, K., and Mann, M. 1994. Metamorphosin A: A novel peptide controlling development of the lower metazoan Hydractinia echinata (Coelenterata, Hydrozoa). Dev. Biol. 163: 440-446.

Liang, P. and Pardee, A.B. 1992. Differential display of eukaryotic messenger RNA by means of the polymerase chain reaction. Science 257: 967-971.

Lohmann, J., Schickle, H., and Bosch, T.C. 1995. REN display, a rapid and efficient method for nonradioactive differential display and mRNA isolation. Biotechniques 18: 200-202.

Lohmann, J.U., Endl, I., and Bosch, T.C. 1999. Silencing of developmental genes in Hydra. Dev. Biol. 214: 211-214.

MacWilliams, H.K. 1983a. Hydra transplantation phenomena and the mechanism of Hydra head regeneration. I. Properties of the head inhibition. Dev. Biol. 96: 217-238.

- 1983b. Hydra transplantation phenomena and the mechanism of Hydra head regeneration. II. Properties of the head activation. Dev. Biol. 96: 239-257.

Martinez, D.E., Dirksen, M.L., Bode, P.M., Jamrich, M., Steele, R.E., and Bode, H.R. 1997. Budhead, a fork head/HNF-3 homologue, is expressed during axis formation and head specification in hydra. Dev. Biol. 192: 523-536.

Meinhardt, H. 1993. A model for pattern formation of hypostome, tentacles, and foot in hydra: How to form structures close to each other, how to form them at a distance. Dev. Biol. 157: 321-333.

Müller, W.A. 1995. Competition for factors and cellular resources as a principle of pattern formation in Hydra. I. Increase of the potentials for head and bud formation and rescue of the regeneration-deficient mutant reg- 16 by treatment with diacylglycerol and arachidonic acid. Dev. Biol. 167: 159-174.

Otto, J.J. and Campbell, R.D. 1977. Tissue economics of hydra: Regulation of cell cycle, animal size and development by controlled feeding rates. J. Cell Sci. 28: 117-132.

Schaller, H. 1973. Isolation and characterization of a low-molecular-weight substance activating head and bud formation in hydra. J. Embryol. Exp. Morphol. 29: 27-38.

Shenk, M.A., Bode, H.R., and Steele, R.E. 1993. Expression of Cnox-2, a HOM/HOX homeobox gene in hydra, is correlated with axial pattern formation. Development 117: 657-667.

Sugiyama, T. 1982. Roles of head activation and head inhibition potentials in pattern formation of hydra: Analysis of a multiheaded mutant strain. Am. Zool. 22: 27-34.

Sugiyama, T. and Fujisawa, T. 1977. Genetic analysis of developmental mechanisms in hydra. III. Characterization of a regeneration deficient strain. J. Embryol. Exp. Morphol. 42: $65-77$.

Takahashi, T., Muneoka, Y., Lohmann, J., Lopez de Haro, M.S., Solleder, G., Bosch, T.C., David, C.N., Bode, H.R., Koizumi, O., Shimizu, H., et al. 1997. Systematic isolation of peptide signal molecules regulating development in hydra: LWamide and PW families. Proc. Natl. Acad. Sci. 94: 1241-1246.

Takahashi, T., Koizumi, O., Ariura, Y., Romanovitch, A., Bosch, T.C., Kobayakawa, Y., Mohri, S., Bode, H.R., Yum, S., Hatta, M., et al. 2000. A novel neuropeptide, Hym-355, positively regulates neuron differentiation in Hydra. Development 127: 997-1005.

Technau, U. and Bode, H.R. 1999. HyBra1, a Brachyury homologue, acts during head formation in Hydra. Development 126: $999-1010$.

Weinziger, R., Salgado, L.M., David, C.N., and Bosch, T.C. 1994. $\mathrm{Ks1}$, an epithelial cell-specific gene, responds to early signals of head formation in Hydra. Development 120: 2511-2517.

Yum, S., Takahashi, T., Hatta, M., and Fujisawa, T. 1998a. The structure and expression of a preprohormone of a neuropeptide, Hym-176 in Hydra magnipapillata. FEBS Lett. 439: 3134.

Yum, S., Takahashi, T., Koizumi, O., Ariura, Y., Kobayakawa, Y., Mohri, S., and Fujisawa, T. 1998b. A novel neuropeptide, Hym-176, induces contraction of the ectodermal muscle in Hydra. Biochem. Biophys. Res. Commun. 248: 584-590. 


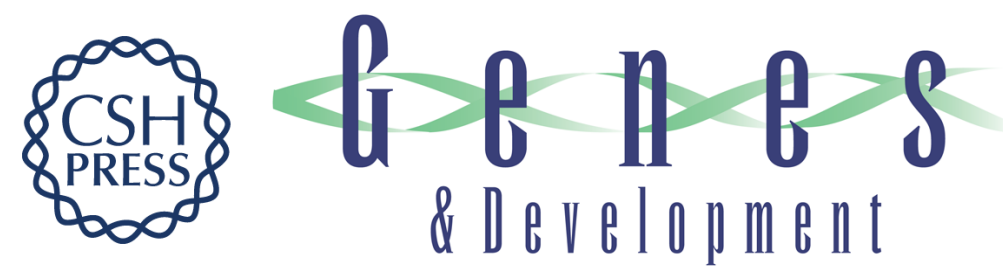

\section{The novel peptide HEADY specifies apical fate in a simple radially symmetric metazoan}

Jan U. Lohmann and Thomas C.G. Bosch

Genes Dev. 2000, 14:

Access the most recent version at doi:10.1101/gad.830100

References This article cites 35 articles, 13 of which can be accessed free at: http://genesdev.cshlp.org/content/14/21/2771.full.html\#ref-list-1

License

Email Alerting

Receive free email alerts when new articles cite this article - sign up in the box at the top Service right corner of the article or click here.

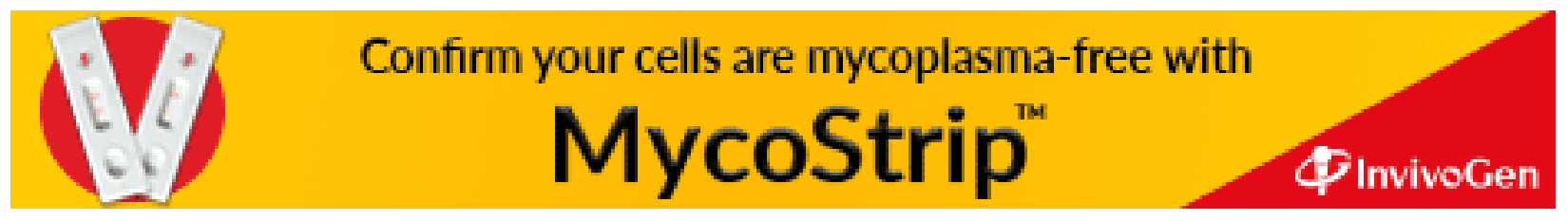

